\title{
๖The Lifecycle of Nonlinear Internal Waves in the Northwestern South China Sea
}

\author{
JIANJUN LIANG \\ Key Laboratory of Digital Earth Science, Institute of Remote Sensing and Digital Earth, Chinese Academy of \\ Sciences, Beijing, China

\section{XIAO-MING LI} \\ Key Laboratory of Digital Earth Science, Institute of Remote Sensing and Digital Earth, Chinese Academy of \\ Sciences, Beijing, and Laboratory for Regional Oceanography and Numerical Modeling, Qingdao National \\ Laboratory for Marine Science and Technology, Qingdao, and Hainan Key Laboratory of Earth Observation, Sanya, China
}

\section{JIN SHA}

Key Laboratory of Digital Earth Science, Institute of Remote Sensing and Digital Earth, Chinese Academy of Sciences, Beijing, China

TONG JIA

Key Laboratory of Digital Earth Science, Institute of Remote Sensing and Digital Earth, Chinese Academy of Sciences, and University of Chinese Academy of Sciences, Beijing, China

\section{YONGZHENG REN}

Key Laboratory of Digital Earth Science, Institute of Remote Sensing and Digital Earth, Chinese Academy of Sciences, Beijing, and Hainan Key Laboratory of Earth Observation, Sanya, China

(Manuscript received 5 November 2018, in final form 28 April 2019)

\begin{abstract}
The life cycle of nonlinear internal waves (NIWs) to the southeast of Hainan Island in the northwestern South China Sea is investigated using synergistic satellite observations, in situ measurements, and numerical simulations. A three-dimensional, fully nonlinear and nonhydrostatic model with ultrafine resolution shows that a diurnal internal tide emanates from a sill in the Xisha Islands at approximately $215 \mathrm{~km}$ away from the local shelf break. The internal tide transits the deep basin toward the shelf break and reflects at the sea bottom and seasonal thermocline in the form of a wave beam. Arriving at the shelf break, the internal tide undergoes nonlinear transformation and produces an undular bore. Analyses of in situ measurements reveal that the undular bore appears as sharp depressions of the strong near-surface seasonal thermocline. The undular bore gradually evolves into an internal solitary wave train on the midshelf, which was detected by the spaceborne synthetic aperture radar. This finding has great implications for investigating NIWs in other coastal oceans where waves are controlled by remotely generated internal tides.
\end{abstract}

\section{Introduction}

Oceanic nonlinear internal waves (NIWs) are common oscillations that travel within the density-stratified ocean with the largest vertical displacement at a pycnocline,

๑ Denotes content that is immediately available upon publication as open access.

Corresponding author: Xiao-Ming Li, lixm@radi.ac.cn where density changes rapidly in the vertical direction. Field measurements and satellite observations show that NIWs are a ubiquitous feature in worldwide marginal seas and coastal regions (Brandt et al. 1997; Jackson 2004; Helfrich and Melville 2006). By inducing large isopycnal displacements and velocities (Osborne and Burch 1980; Klymak et al. 2006) and triggering intense mixing (Sandstrom and Oakey 1995; Inall et al. 2000; MacKinnon and Gregg 2003; Moum et al. 2003), NIWs play a key role in transporting nutrients (Sandstrom and 


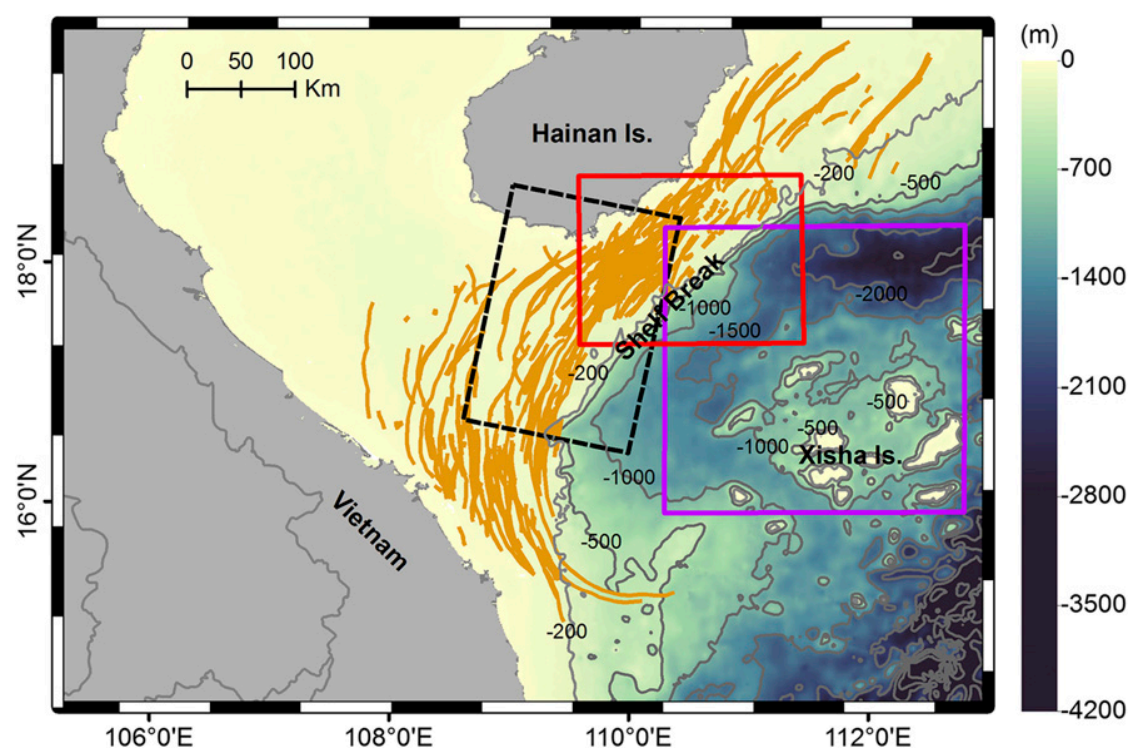

FIG. 1. Spatial distribution of NIW occurrences in the northwestern SCS based on wave crests (orange curves) observed in multiple ENVISAT/ASAR and ALOS/PALSAR images acquired between 2003 and 2011. The red rectangle marks the area of interest (AOI) for this study. The magenta rectangle marks the domain of numerical modeling (presented in section 4) with ultrafine resolution. The black dashed rectangle marks the entire spatial coverage of the GF-3 SAR image presented in Fig. 2a. The shaded color indicates the water depth.

Elliott 1984), suspending sediments (Bogucki et al. 1997), and affecting acoustic propagation (Chiu et al. 2004). Moreover, because NIWs are a major sink for locally or remotely generated internal tides (Nash et al. 2012; Lamb 2014; Vlasenko et al. 2014), which transport globally significant amounts of energy necessary to maintain meridional overturning circulation (Munk and Wunsch 1998; Egbert and Ray 2000; Alford 2003), a precise understanding of NIW dynamics is vital to quantifying their role in determining the global geography of diapycnal mixing (MacKinnon et al. 2017).

The northern South China Sea (SCS) forms the most active NIWs (Jackson 2004; Guo and Chen 2014) among global oceans, due to the intense interactions of strong tidal currents and sharp topographic variations in the Luzon Strait. Thus far, a sufficiently detailed "cradle-to-grave" picture of NIWs in the northeastern SCS has emerged. The barotropic tide moves a stratified water column across the two shallow ridges in the Luzon Strait, where nearly sinusoidal internal tides are generated (Alford et al. 2015). The internal tides eventually evolve to form NIWs under the influence of nonhydrostatic and rotational dispersion in the deep basin (Helfrich and Grimshaw 2008; Alford et al. 2010; Li and Farmer 2011). Subsequently, NIWs diffract and refract on the Dongsha Plateau (Li et al. 2013; Jia et al. 2018), dissipating most of their energy (Chang et al. 2006). Continuing with westward propagation, the NIWs experience a polarity conversion when the pycnocline is below the middepth (Liu et al. 1998).

Apart from the northeastern SCS, the northwestern SCS has also been identified as a hot spot of NIW occurrences as revealed by synthetic aperture radar (SAR) observations (Fig. 1) and previous studies (Liu and Hsu 2004; Wang et al. 2013). Various explanations of the generation of NIWs have been presented, and they mainly include (i) local generation by diurnal internal tides originating from the shelf break northeast of Hainan Island (Xu et al. 2010), (ii) local generation by semidiurnal barotropic tidal flows interacting with sills in the middle of the SCS (Li et al. 2011), (iii) local generation by semidiurnal or diurnal barotropic tidal flows interacting with the arc-like continental slope south of Hainan Island (Xu et al. 2016), and (iv) remote generation from the Luzon Strait (Li et al. 2008). Therefore, in contrast with the generally accepted generation and evolution mechanisms of NIWs in the northeastern SCS, the scientific understanding of where the NIWs in the northwestern SCS originate and how they evolve remains under debate.

In this study, we investigate the life cycle of NIWs southeast of Hainan Island (red rectangle in Fig. 1), where spaceborne SAR observations suggest a high concentration of NIW occurrences in the northwestern SCS. The synergistic use of four spaceborne SARs, in situ measurements and an ultrafine resolution numerical 
simulation provides comprehensive three-dimensional information for NIWs in the study area and supports for drawing solid conclusions. The paper is structured as follows. In section 2, we first present the spaceborne SAR observations of NIWs on the midshelf with water depth of approximately $80 \mathrm{~m}$, followed by a presentation of their preceding in situ measured counterparts on the outer shelf (approximately 130-m deep) in section 3. Then section 4 presents the source site and wave dynamics from the source site to the outer shelf by a three-dimensional, fully nonlinear and nonhydrostatic simulation based on the MITgcm (Marshall et al. 1997). A discussion is presented in section 5, and the conclusions are drawn in section 6 .

\section{Satellite observations of NIWs on the midshelf}

\section{a. Spaceborne SAR data}

NIWs are a readily detectable phenomenon in SAR images due to the wave-induced patterns of the sea surface roughness. Here, spaceborne SAR images over the area of interest (AOI) were acquired by the two $\mathrm{X}$-band (microwave frequency of $9.8 \mathrm{GHz}$ ) SARs of COSMO-SkyMed (CSK) and TerraSAR-X (TSX) and the two C-band $(5.6 \mathrm{GHz})$ SARs of GaoFen-3 (GF-3) and RADARSAT-2 (R2). The GF-3 (Fig. 2a), CSK (Fig. 2b), and TSX (Fig. 2c) SAR data were acquired on 10 June 2017 and the R2 (Fig. 2d) data were acquired on 11 June 2017. Technical specifications of the four SAR images are listed in Table 1. All the four SAR images were processed by steps of radiometric calibration, speckle filtering, and geolocation. The internal wave crests extracted from the CSK and the GF-3 SAR images are depicted in Fig. 2e.

\section{b. Wave characteristics derived from SAR images}

The GF-3 SAR image (Fig. 2a) shows the clearest signature of NIWs among the four SAR images because of its superior spatial resolution of $8 \mathrm{~m}$. Hence, we mainly use the $G F-3$ SAR image to investigate the internal wave characteristics. The $G F-3$ SAR image revealed a strong NIW train, labeled P1 in Fig. 2a, and it was manifested as bright stripes preceding dark stripes in the direction of wave propagation. The clear bright-dark signature suggests that the NIWs are of the first mode depression type (Alpers 1985; Jackson et al. 2013). Furthermore, we found that it traveled toward approximately $294^{\circ}$ (clockwise relative to north) by applying the fast Fourier transform (FFT) analysis to a subscene of the GF-3 SAR image containing the wave packet $\mathrm{P} 1$. The propagation direction of the NIWs corresponds to the peak of the FFT spectrum (symmetric ambiguity is eliminated because these NIWs were propagating onshore).
Since the TSX and GF-3 SAR images were acquired at a temporal interval of $11 \mathrm{~min}$, we can obtain an accurate phase speed of the leading wave in the wave train P1 by measuring the distance between the two points where the positive peak locates in the radar backscattering section profiles in the two sequential images. The phase speed of the leading wave in the wave train P1 is $0.66 \mathrm{~m} \mathrm{~s}^{-1}$, which is close to the horizontal phase speed of the first baroclinic mode using the observed background stratification at a water depth of $74 \mathrm{~m}$ (Gill 1982).

In addition, the GF-3 SAR image reveals three clear set of wave trains and the distance between two neighboring wave trains is approximately $6 \mathrm{~km}$. The three wave trains are probably generated in one diurnal period and come from different internal bores generated at different stages in the shoaling of a diurnal internal tide, suggested by intermittent bursts of strong currents (see Fig. 4a) and the numerical results in section 4. Each internal bore was proposed to evolve into one wave train according to the Korteweg-de Vries (KdV) type theory (Helfrich and Melville 2006). The packet P1 contains more than five rank-ordered NIWs whose wavelengths appear to be monotonically decreasing from front to rear from $1.2 \mathrm{~km}$ to $300 \mathrm{~m}$.

In summary, by analyzing the spaceborne SAR image signatures, phase speeds, and rank-ordered nature of the NIWs, we conclude that the NIWs on the midshelf to the southeast of Hainan Island are the first mode internal solitary waves of depression.

\section{In situ measurements of NIWs on the outer shelf}

\section{a. Data processing of in situ measurements}

The field experiment took place southeast of Hainan Island from 10 to 12 June 2017 during a spring tide. The setup of the observation aims to reveal the characteristics of NIWs on the outer shelf where the water depth is approximately $130 \mathrm{~m}$. The research vessel was equipped with a temperature chain constructed by binding 13 RBR temperature-depth/temperature sensors and 1 ALEC temperature-depth sensor onto a cable. The instruments recorded at depth intervals of approximately $5 \mathrm{~m}$ in the top $50 \mathrm{~m}$ and $15-20 \mathrm{~m}$ below this depth. The minimum depth was $5 \mathrm{~m}$, and the maximum depth was $120 \mathrm{~m}$. The sampling rate of the sensors was set at a frequency of $0.1 \mathrm{~Hz}$ to ensure that high-frequency NIWs are resolved. Continuous yo-yo profiles were obtained by deploying a conductivity-temperature-depth (CTD) profiler (type: RINKO-Profiler ASTD102) sampled at a frequency of $10 \mathrm{~Hz}$. An environmental mooring equipped with an upward-looking 600-KHz Seaguard II Doppler current profiler at 36-m depth was deployed at S1 (located at $18.00^{\circ} \mathrm{N}, 110.27^{\circ} \mathrm{E}$, marked by the red dot in Fig. 2a) on 

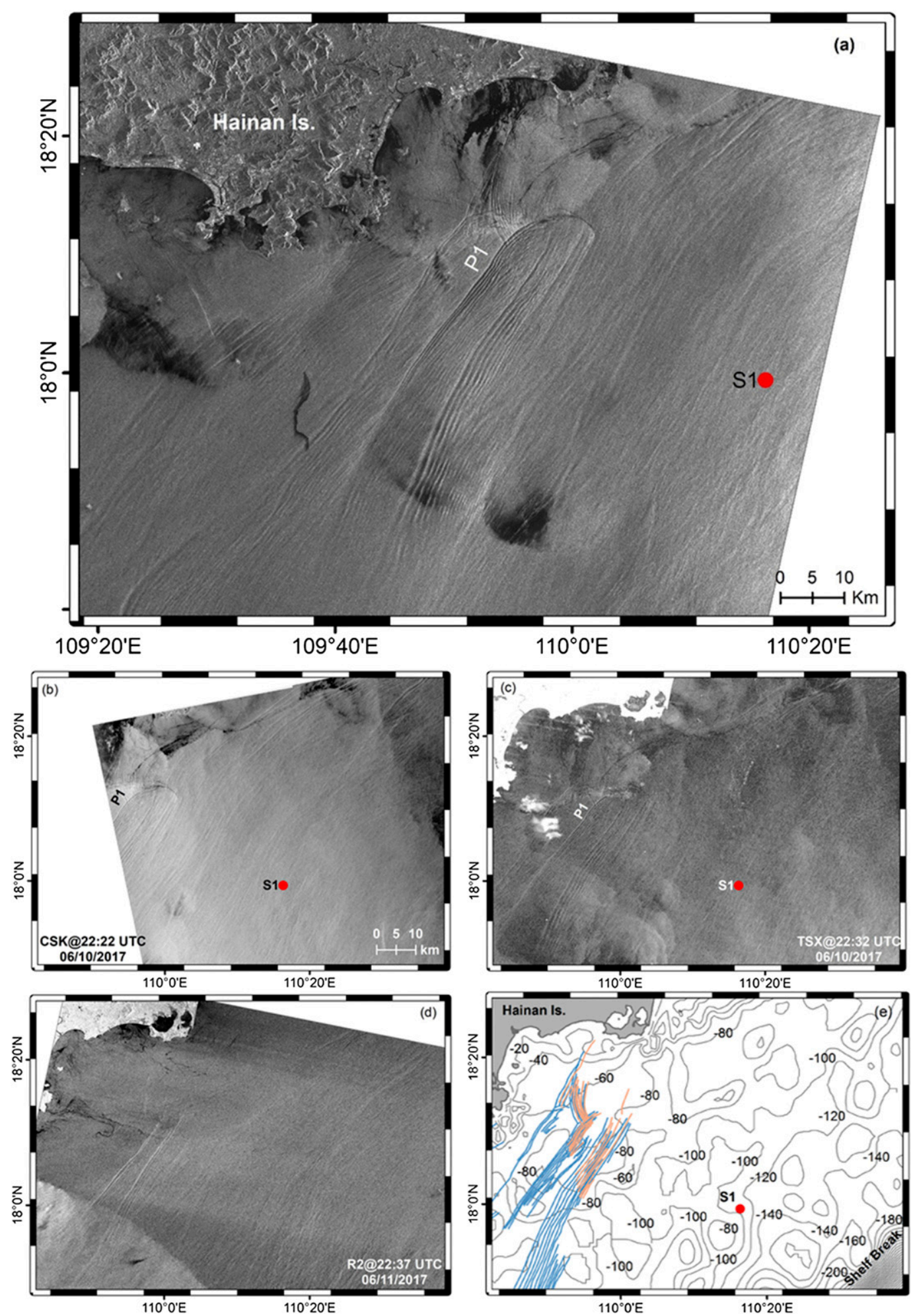

FIG. 2. (a) Portion of the GF-3 SAR image acquired at 2243 UTC 10 Jun 2017 in the AOI, whose entire spatial coverage is represented by the black rectangle in Fig. 1. The life cycle of the NIW packet labeled P1 is investigated in this study. The red dot, labeled S1, denotes the position of in situ measurements obtained on 10 Jun 2017. The acquired (b) CSK, (c) TSX, and (d) $R 2$ spaceborne SAR images used in this study. The light blue and fire red lines in (e) represent the crests of NIWs extracted from the CSK SAR and GF-3 SAR images. 
TABLE 1. Technical specifications of the spaceborne SAR data acquired in this study.

\begin{tabular}{lclc}
\hline \hline SAR & Acquisition time and date & \multicolumn{1}{c}{ Imaging mode } & Resolution (range azimuth) \\
\hline CSK & 2222 UTC 10 Jun 2017 & Wide region ScanSAR & $20 \mathrm{~m} \times 20 \mathrm{~m}$ \\
$T S X$ & 2232 UTC 10 Jun 2017 & ScanSAR & $36 \mathrm{~m} \times 36 \mathrm{~m}$ \\
$G F-3$ & 2243 UTC 10 Jun 2017 & Standard stripmap & $8 \mathrm{~m} \times 8 \mathrm{~m}$ \\
$R 2$ & 2237 UTC 11 Jun 2017 & Wide swath beam & $25 \mathrm{~m} \times 25 \mathrm{~m}$ \\
\hline
\end{tabular}

10 June 2017 and at 62-m depth on 11 June 2017. The Doppler current profiler data were acquired every $2 \mathrm{~min}$ with ensemble averages and a 1-m vertical bin size.

The in situ data presented here were collected on 10 June 2017. The temperature data were averaged at 1-min intervals and interpolated to standard depths with an interval of $1 \mathrm{~m}$. Then, a low-pass filter was applied to reduce noise. The current data were first decomposed into onshore and across-shore components according to the SAR-derived wave propagation direction of $294^{\circ}$. Then, we removed the velocity perturbations with periods longer than $6 \mathrm{~h}$ using a combination of FFT and nonlinear curve fitting algorithms. Eventually, we obtained the velocity perturbations of NIWs by reducing the high frequency noise using a low-pass filter.

The mean temperature (Fig. 3a) and salinity (Fig. 3b) profiles were derived from the ASTD 102 casts during the experimental period. Substituting the mean temperature and salinity data into the Thermodynamic Equation of Seawater 2010 (IOC/SCOR/IAPSO 2010) leads to the background stratification profile, in which a strong near-surface pycnocline develops (Fig. 3c).

\section{b. Wave characteristics from in situ measurements}

The consecutive spaceborne SAR observations suggest that the NIWs propagated from the outer shelf to the midshelf. Thus, the waves should have passed the in situ station $\mathrm{S} 1$ earlier than those observed by the $G F-3$ SAR. If the wave propagates uniformly at $0.89 \mathrm{~m} \mathrm{~s}^{-1}$, estimated from the in situ measurements (Helfrich and Melville 2006) and given that the spatial distance is $44.7 \mathrm{~km}$, the packet $\mathrm{P} 1$ should have passed the $\mathrm{S} 1$ station at 0846 UTC 10 June 2017. If the wave propagates uniformly at $0.66 \mathrm{~m} \mathrm{~s}^{-1}$, estimated from the SAR observations on the midshelf, the packet $\mathrm{P} 1$ should have passed the S1 station at 0354 UTC 10 June 2017. In fact, the propagation speed slowly decreases from 0.89 to $0.66 \mathrm{~m} \mathrm{~s}^{-1}$ due to the slowly decreasing water depth. As a result, the packet P1 should have passed the S1 station at a time from 0354 to 0846 UTC 10 June 2017. A detailed inspection of the onshore current profiles from -32 to $-8 \mathrm{~m}$ (Fig. 4a) reveals that only one strong NIW emerged at 0507 UTC 10 June, and it was intermediate between the predicted limits. The NIW is characterized by a positive onshore velocity profile above the seasonal thermocline. The magnitude of the upper layer velocity is also consistent with the two-layer KdV theory (Holloway 1987), in which the wave amplitude is estimated to be $5 \mathrm{~m}$, the linear phase speed is $0.80 \mathrm{~m} \mathrm{~s}^{-1}$ and the upper layer thickness is $29 \mathrm{~m}$. Meanwhile, the NIW passing the S1 station was captured by the temperature chain onboard the drifting research vessel half an hour later (i.e., at 0535 UTC) (Fig. 4b), when the vessel was just $3 \mathrm{~km}$ to the northwest of the $\mathrm{S} 1$ station. The temperature profiles suggest that the recorded NIW is an internal undular bore that induces sharp depressions of the strong seasonal thermocline (Small et al. 1999b; Colosi et al. 2001; Shroyer et al. 2011). An undular bore features unsteady and gregarious undulations linking an initial nonlinear internal tide and the final evolution into an internal solitary wave train.

In summary, analyses of the in situ measurements suggest that the NIW on the outer shelf is an undular bore of depression that propagated along the strong near-surface seasonal thermocline.

\section{Numerical modeling of NIWs and internal tide dynamics from source site to outer shelf}

The former sections 2 and 3 demonstrate the propagation of NIWs from the outer shelf to midshelf. In this section, we present a three-dimensional, fully nonlinear and nonhydrostatic modeling based on the MITgem to demonstrate the source site of the observed NIWs and how the internal tide evolves, thereby generating NIWs from the source site to the outer shelf.

\section{a. Model setup}

The in situ measurements suggest that the NIWs had a wavelength on the order of approximately $1000 \mathrm{~m}$ (computed by $0.89 \mathrm{~m} \mathrm{~s}^{-1}$ times $20 \mathrm{~min}$, a typical wave period revealed by Fig. 4a) on the outer shelf, which demands a numerical model that possesses a horizontal resolution of at least $100 \mathrm{~m}$ or better to resolve the NIWs. The $G F-3$ SAR image on 10 June and $R 2$ SAR image on 11 June (Table 1 ), which are separated by $24 \mathrm{~h}$, show nearly identical NIW signatures with small spatial displacements between the two images. The coincidence of these patterns imaged at similar times during a tidal cycle, suggests that the waves are tidally generated. To determine the domain that the model should cover, we 

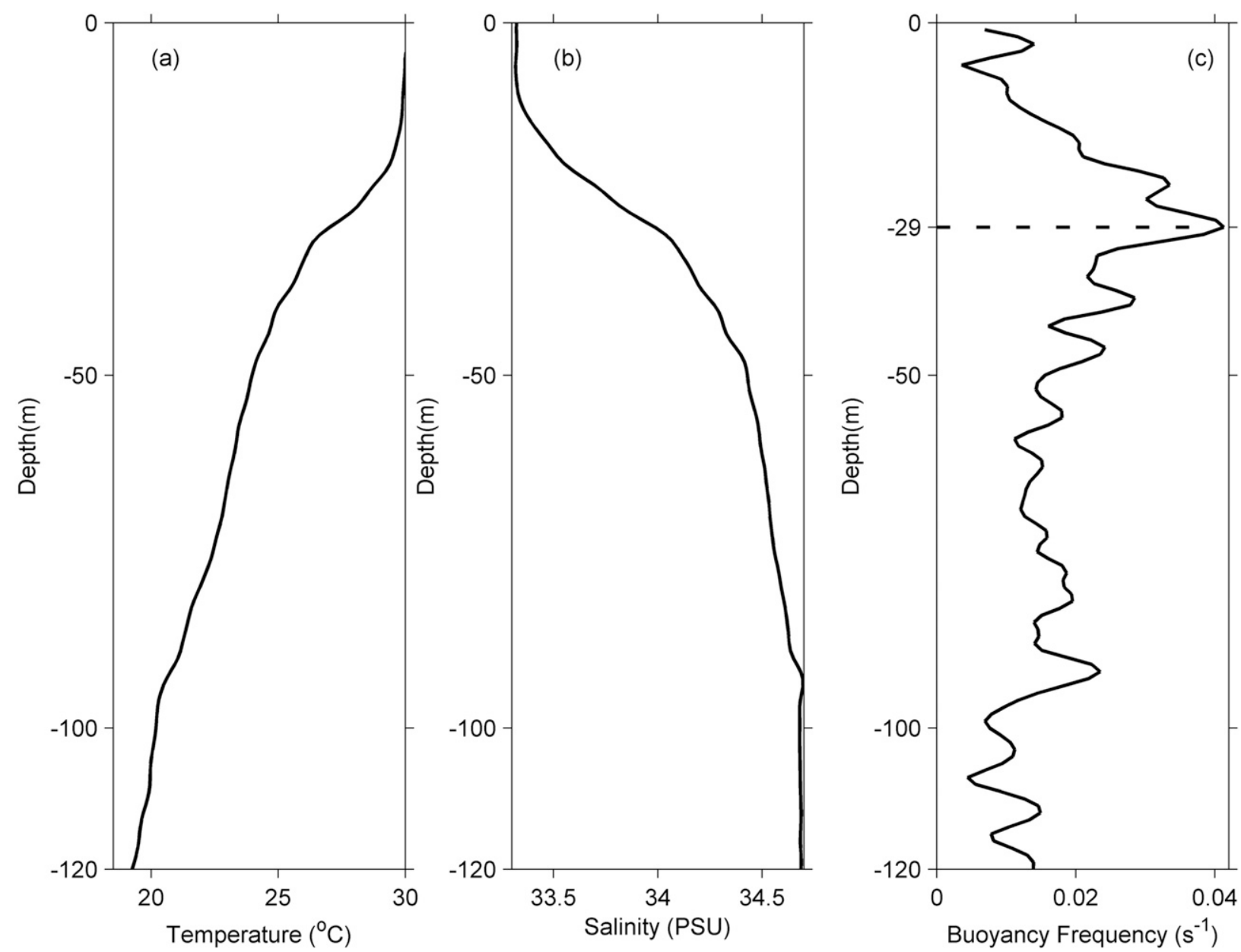

FIG. 3. Mean (a) temperature, (b) salinity, and (c) buoyancy frequency acquired from ASTD measurements during the in situ experiments on 10-12 Jun 2017. The dashed line in (c) suggests the depth of the near-surface pycnocline.

need to identify the most likely location where the NIWs are generated. For that purpose, we calculate the internal tide generating force $F$ proposed by Baines (1982):

$$
F=z N^{2} \int \mathbf{Q} d t \cdot \nabla\left(\frac{1}{h_{b}}\right)
$$

where $z$ is the vertical depth; $N$ is the buoyancy frequency; $\mathbf{Q}=\left(Q_{x}, Q_{y}\right)=\left(-u_{b} h_{b},-v_{b} h_{b}\right)$ is the barotropic tidal volume flux; $u_{b}$ and $v_{b}$ denote the zonal and meridional components of the barotropic velocity, respectively; and $h_{b}$ is the water depth. The barotropic tide currents were extracted from the $1 / 30^{\circ}$-resolution inverse tidal model for the China Seas, the TPXO_CS_ATLAS (Egbert and Erofeeva 2002). The merged mean temperature data (Fig. 3a) and the $1 / 4^{\circ}$-resolution World Ocean Atlas 2013 (WOA13) data (Locarnini et al. 2013) were used to calculate the buoyancy frequency. We obtained the bathymetry data from the 30-arc-s SRTM30_PLUS
(Smith and Sandwell 1997). The computed internal tide generating force (Fig. 5) is strong in the Xisha Islands but negligible near the local shelf break, implying that the Xisha Islands is the source site of the observed NIWs in both the SAR images and in situ measurements. Therefore, the numerical model is tidally driven and includes both the local outer shelf and remote Xisha Islands in an approximately 215-km-long region with a grid resolution of $100 \mathrm{~m}$ to ensure accurate simulations of the observed NIWs.

The MITgcm was used in the three-dimensional, fully nonlinear and nonhydrostatic configuration. The eastwest (north-south) length of the model domain is approximately $1540 \mathrm{~km}(800 \mathrm{~km})$. The model domain is composed of an ultrafine-resolution inner region (represented by the magenta rectangle in Fig. 1) and a telescoped outer region with the four open boundaries located at $104.3^{\circ} \mathrm{E}, 118.8^{\circ} \mathrm{E}, 13.5^{\circ} \mathrm{N}$, and $20.7^{\circ} \mathrm{N}$. The inner region, including the Xisha Islands and shelf break, is in the center of the domain. The simulation of 

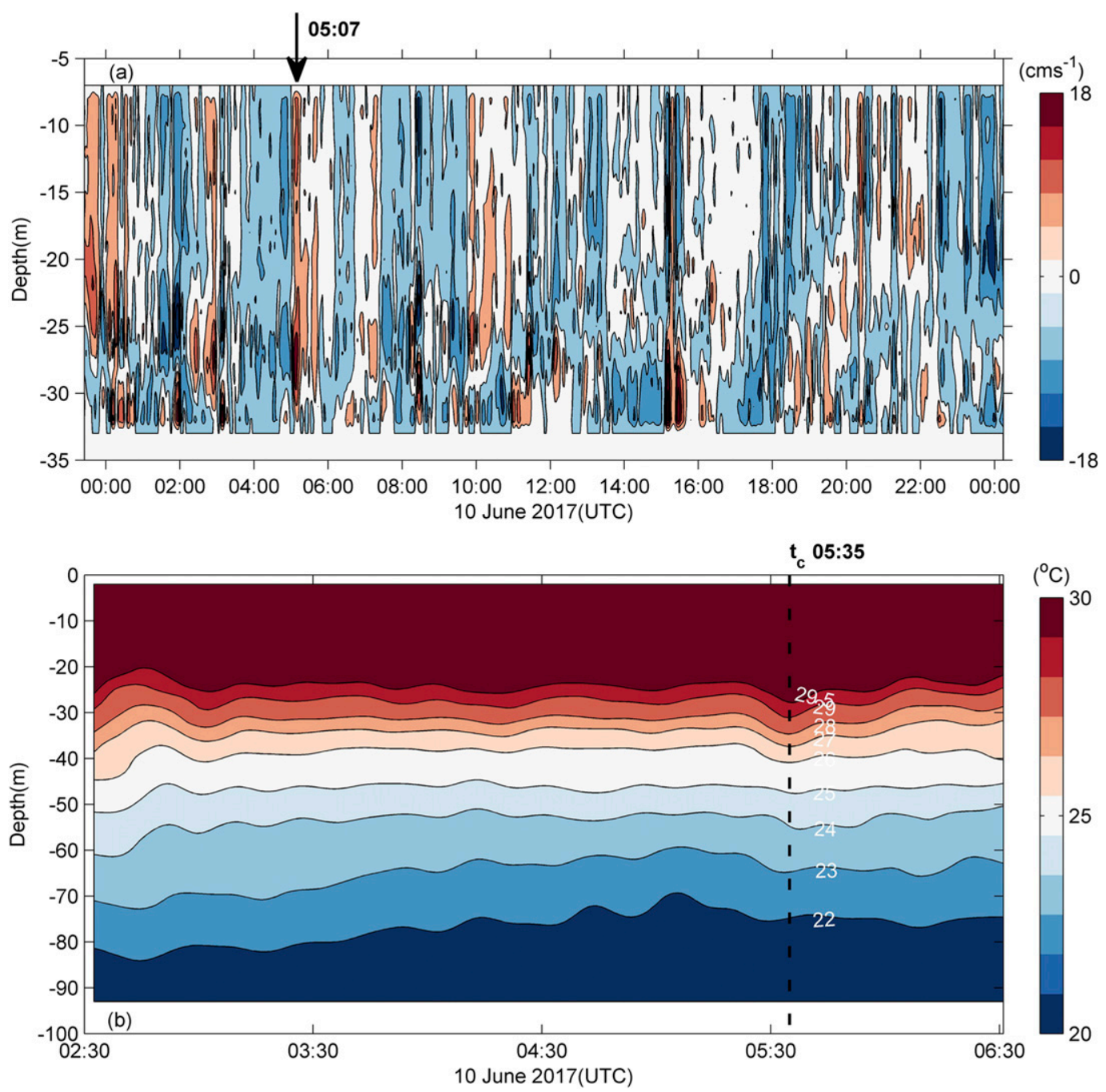

FIG. 4. In situ measurements of water current at the S1 station and temperature near the S1 station. The local water depth is $130 \mathrm{~m}$. (a) Depth-time series of onshore currents from 2325 UTC 9 Jun to 0014 UTC 11 Jun 2017. The arrow points to the NIW that would propagate onshore and be observed in the GF-3 SAR image as the packet P1 in Fig. 2a. (b) Depth-time series of water temperature relative to the drifting ship. Parameter $t_{c}$ denotes 0535 UTC 10 Jun when the NIW that passed the S1 station. Note that the NIW was trapped in the strong seasonal thermocline (Fig. 3c).

the inner region has a horizontal grid resolution of $100 \mathrm{~m}$ (zonal direction) $\times 250 \mathrm{~m}$ (meridional direction). Away from the inner region, the horizontal grid in the zonal (meridional) direction is telescoped to reach a maximum of $8.6(6.9) \mathrm{km}$ at the model boundaries. In the vertical direction $150 z$ levels were used with $\Delta z=5$-m resolution in the upper 200-m layer. Another $\Delta z=10$-m resolution was used in the 300-m layer, followed by 26 layers with $\Delta z=20$-m resolution and 41 layers with $\Delta z=50$-m resolution. Finally, the bottom 13 layers had a resolution of $\Delta z=150 \mathrm{~m}$. The model features a subgridscale scheme that computes vertical viscosities and diffusivities above background values of $10^{-5} \mathrm{~m}^{2} \mathrm{~s}^{-1}$ through
Thorpe sorting of unstable density profiles (Klymak and Legg 2010). The horizontal viscosity and diffusivity are $10^{-2}$ and $10^{-4} \mathrm{~m}^{2} \mathrm{~s}^{-1}$. The quadratic bottom drag is set to 0.0025 .

The model was initialized with a horizontally uniform stratification derived from the merged mean temperature data (Fig. 3a) and the WOA13. In the model, the density is only a linear function of temperature. The model bathymetry is obtained from the SRTM30_PLUS. The model is forced at its domain boundaries by a 7-day time series of the zonal and meridional barotropic velocities constructed from the TPXO_SCS_ATLAS. To allow for the inward propagation of the tidal barotropic waves 


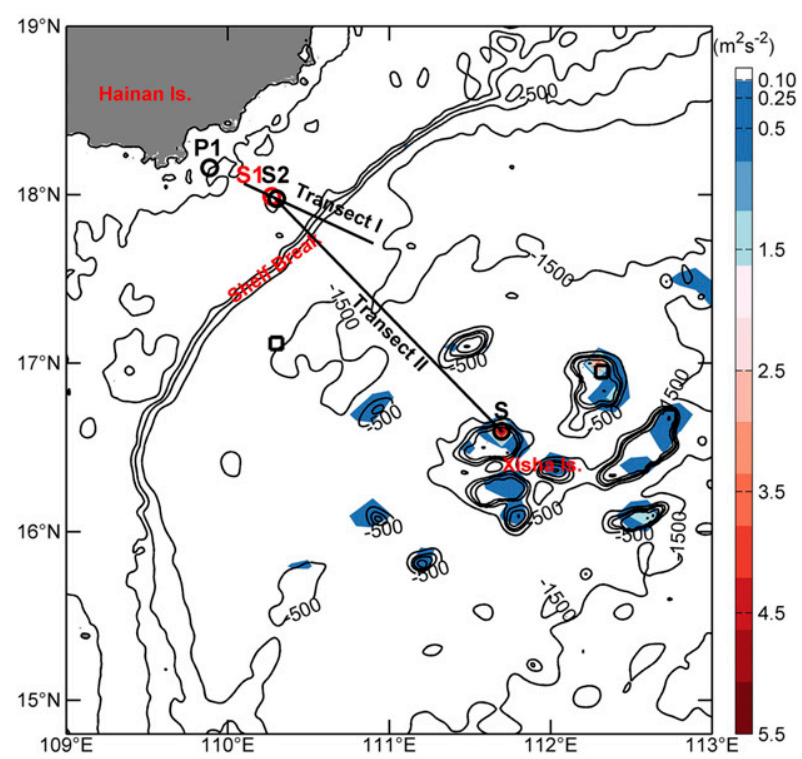

FIG. 5. Map of the maximum depth-integrated internal tide generating force over the tidal cycle on 10 Jun 2017. Depth contours are shown in meters. Transect I and Transect II denote the vertical sections used to depict the numerical results in Fig. 6 and Fig. 7, respectively. P1 is the location of NIWs observed by the $G F-3$ SAR. S2 $\left(17.976^{\circ} \mathrm{N}, 110.303^{\circ} \mathrm{E}\right)$ is the predicted arrival location of the simulated NIW in Fig. 6 according to the field observations at $\mathrm{S} 1$. The letter $\mathrm{S}\left(16.596^{\circ} \mathrm{N}, 111.696^{\circ} \mathrm{E}\right)$ is the predicted source site with the strongest internal tide generation and the origin of ray paths depicted in Fig. 7.

while damping the outward-propagating baroclinic waves, the interior velocity fields are quadratically nudged to the barotropic tidal velocities over 22 cells in from the boundaries along the zonal direction and 16 cells along the meridional direction (Lavelle and Thacker 2008). The interior temperature is nudged to a time-invariant temperature profile at the boundaries. In a test run, we found that the effect of wave reflections is minimized for a nudging time scale of $5400 \mathrm{~s}$. The simulations contained 657 million grid cells and took 22 days on 360 processors to run 6 model days without interruption.

\section{b. Results of the numerical modeling}

\section{1) UNDULAR BORE ON THE OUTER SHELF}

The measurements at the S1 station recorded a NIW at 0507 UTC 10 June 2017 (Fig. 4a). Then, its arrival location at 0400 UTC 10 June 2017 is predicted at $17.976^{\circ} \mathrm{N}, 110.303^{\circ} \mathrm{E}$ (i.e., S2 marked in Fig. 5) using the NIW's propagation direction of $294^{\circ}$ determined from the SAR observations and the phase speed of $0.89 \mathrm{~m} \mathrm{~s}^{-1}$. By comparison, the numerical modeling results show that the NIW arrived at the location $17.983^{\circ} \mathrm{N}, 110.286^{\circ} \mathrm{E}$ at 0400 UTC 10 June (which is labeled by the arrow in Fig. 6a and located approximately $2.0 \mathrm{~km}$ away from the analytical prediction location S2); thus, the results were consistent. In addition, the simulated horizontal baroclinic velocity $u^{\prime}=u-U$ ( $u$ is the total velocity and $U$ is the depth-independent barotropic component) and temperature in Fig. 6a show that the NIW has a negative current core in the seasonal thermocline, which suggests that the NIW was propagating onshore, and this finding is consistent with the SAR observation. Note that the NIW has a positive current profile in Fig. $4 \mathrm{a}$ where the onshore component in the direction of wave propagation is depicted. Furthermore, a comparison between the simulated horizontal baroclinic velocities and observed ones at the $\mathrm{S} 1$ station shows that they have a similar structure and both achieve the maximum magnitude at the depth of approximately $29 \mathrm{~m}$ (Fig. 6b). However, the model underpredicts the observed $u^{\prime}$ by $30 \%-50 \%$, possibly because the modeled $u^{\prime}$ still contains baroclinic components with periods longer than $6 \mathrm{~h}$ that have been removed in the observed $u^{\prime}$. In short, the model simulates a comparable NIW on the outer shelf.

\section{2) INTERNAL TIDE: From SOURCE SITE TO OUTER SHELF}

Confident in the accuracy of the numerical simulations, the source site was tracked by depicting the internal tide ray path in a vertical section, which is denoted by Transect II in Fig. 5. The ray path is expressed as follows (Cole et al. 2009):

$$
\frac{d x}{d z}=\sqrt{\frac{N^{2}-\omega^{2}}{\omega^{2}-f^{2}}},
$$

where $\omega$ is the tidal angular frequency and $f$ is the Coriolis frequency. The ray paths of the $\mathrm{K}_{1}$ internal tide are shown in Fig. 7. Generally, the ray paths are mostly consistent with the simulated internal tidal beams that are manifested as slanting narrow bands of elevated velocities. The ray originates from the sill crest in the Xisha Islands (denoted by "S" in Fig. 5), where the predicted internal tide generation is the strongest. Then, it slopes downward into the deep ocean, reflects upward from the seafloor at a depth of $1000-1100 \mathrm{~m}$, and reemerges at the seasonal thermocline. The seasonal thermocline makes the ray reflect again (Mathur and Peacock 2009) and the ray continues propagating westward and undergoes a second bottom reflection at a depth of $120 \mathrm{~m}$. Finally, the ray surfaces and arrives at the front of the simulated NIW (blue dashed line in Fig. 7b). Furthermore, Fig. 7b shows that only when the incident internal tide reaches the shelf break region, does it begin to dramatically steepen and undergo strong nonlinear transformation, giving rise to small-scale nonlinear wave perturbations. The internal tide keeps the 

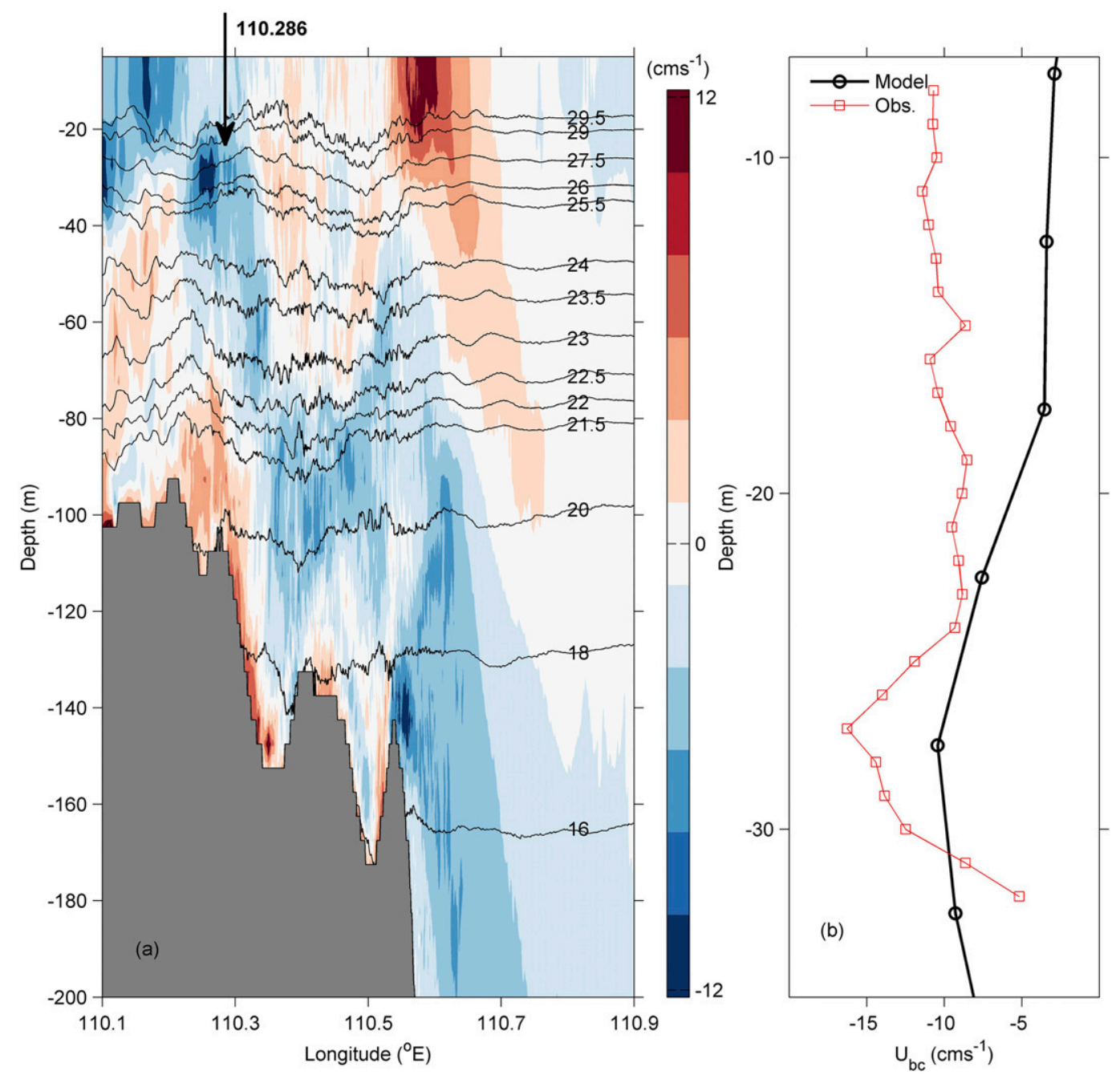

FIG. 6. Numerical simulations of the baroclinic wave field at 0400 UTC 10 Jun 2017 in the Transect I depicted in Fig. 5, which is along $294^{\circ}$ from true north and consistent with the SAR-derived NIW propagation direction at midshelf. (a) Shaded colors represent the horizontal baroclinic velocities, and black lines are contour plots of temperature. The arrow points to the simulated NIW. (b) The dark line with circles denotes the simulated horizontal baroclinic velocity, and the red line with squares denotes the observed horizontal baroclinic velocity at the S1 station.

form of a wave beam without disintegration in the deep ocean. In addition, the numerical results do not show obvious evidence for internal tide generation at the shelf break, which coincides with the analytical computation of the internal tide generating force (Fig. 5).

\section{Discussion}

The abundant internal wave activities accommodated by the northwestern SCS have drawn great research interest and focus; however, these internal wave activities remain less well understood comparing to those emerging in the northeastern SCS. Here, compared to previous studies, we verified the Xisha Islands, rather than the Luzon Strait, as the new source site of NIWs to the southeast of Hainan Island. In addition to our results not supporting the Luzon Strait as the source site, the altimetric energy fluxes of mode- 1 diurnal internal tides computed by Zhao (2014) also show that diurnal internal tides primarily refract southwestward to the equator due to the earth's rotation and probably cannot refract northwestward onto the shelf break to the southeast of Hainan Island, thereby undergoing nonlinear transformation and producing nonlinear bores. Furthermore, we illuminate a believable life cycle of NIWs in the northwestern SCS (Fig. 8) via spaceborne SAR observations, in situ measurements and numerical modeling with an ultrafine resolution. 

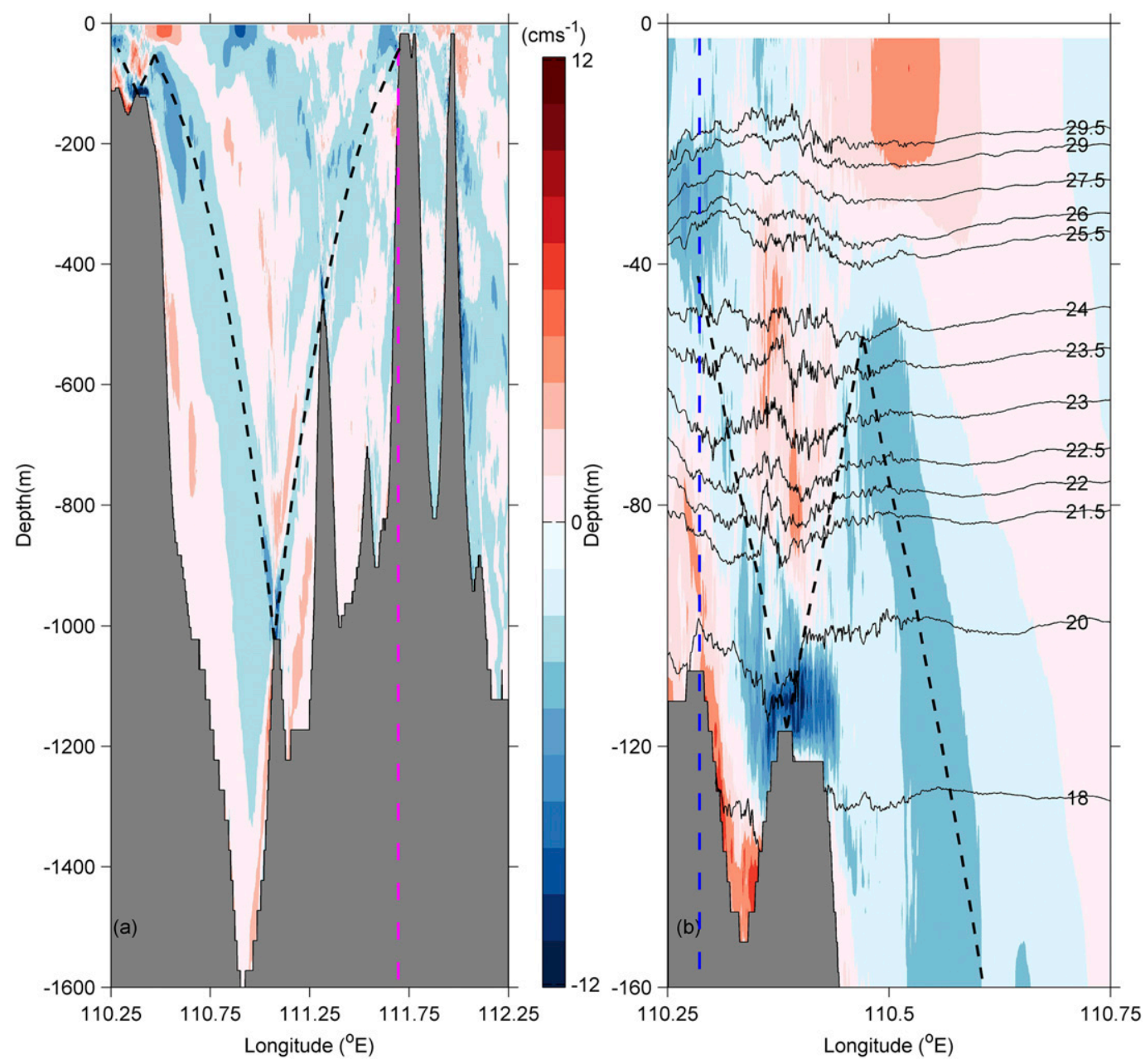

FIG. 7. Numerical simulations of the baroclinic wave field at 0400 UTC 10 Jun 2017 in Transect II depicted in Fig. 5. (a) Shaded colors represent the horizontal baroclinic velocities; the black dashed line represents the ray path of a $\mathrm{K}_{1}$ internal tide; and the magenta dashed line denotes the source site ( $\mathrm{S}$ in Fig. 5), which has the strongest internal tide generation. (b) Zoomed-in portion of shelf break in the upper $160 \mathrm{~m}$ of (a). The blue dashed line denotes the simulated NIW in Fig. 6a, and the black lines represent the contour plots of temperature.

Spaceborne SAR is a powerful instrument for observing NIWs. However, these waves are difficult to capture because the SAR imaging area is a small patch compared with the immense area of the ocean. Due to the irregular acquisitions of spaceborne SAR data, matching in situ measurements with SAR observations becomes more difficult. Moreover, in situ data are particularly important for studying NIWs with three-dimensional structures. In our study, based on the spatial and temporal distribution of NIWs southeast of Hainan Island (Fig. 1), we determined both the season and area in which spaceborne SAR data should be acquired. Fortunately, all planned SAR images were acquired successfully, and all present the desired NIW signatures. More importantly, these SAR data and in situ measurements are synergistic. The most noticeable difference between our work using spaceborne SAR for NIWs and many previous studies is that we can achieve continuous SAR images within approximately $10 \mathrm{~min}$ as well as SAR images with a 24-h interval. The former acquisitions at the minute-scale interval yield accurate derivations of NIW propagation phase speed and direction, while the latter acquisitions are separated by tidal periods and show identical IW patterns, which indicate that these waves are of tidal origin. These insights further guide the appropriate set up of numerical modeling.

A major challenge in simulating tidally generated NIWs is the remarkable range of scales involved, which include NIWs of thousands/hundreds of meters to barotropic tides of thousands of kilometers. Three-dimensional nonhydrostatic models have been widely employed to 


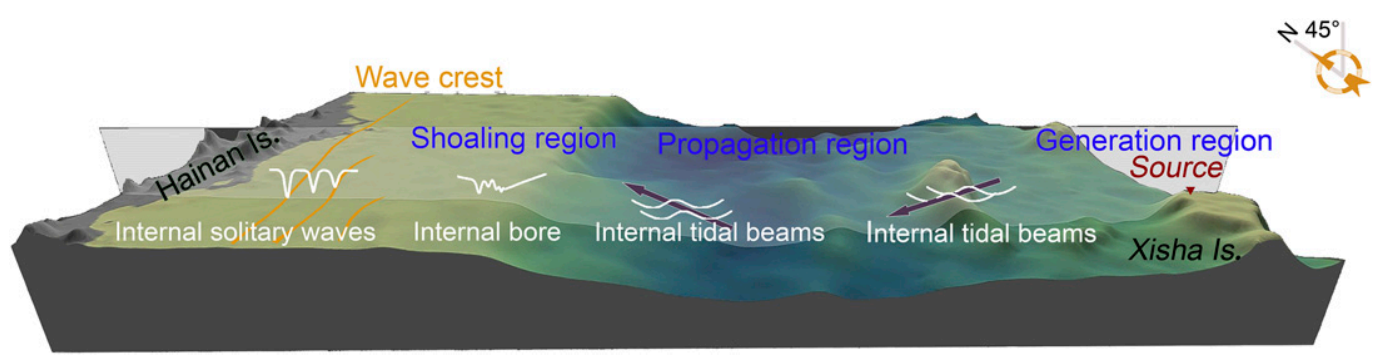

FIG. 8. Schematic diagram of the life cycle of NIWs in the region southeast of Hainan Island. The vertical section is in Transect II depicted in Fig. 5 to include the source site in the Xisha Islands and the observed NIWs on the outer shelf.

simulate the NIWs in the northeastern SCS. These models feature a horizontal grid resolution of $1 \mathrm{~km}$ and contain approximately 10 million grid cells (Simmons et al. 2011). However, Simmons et al. (2011) argues that precise simulations of the NIWs in the northeastern SCS require a horizontal grid resolution of $O(100) \mathrm{m}$ and at least 600 million grid cells. Such a large simulation is highly challenging, and scientists are confronted with a core question as to whether such an effort would produce accurate predictions. Here, to resolve the NIWs, which are approximately $215 \mathrm{~km}$ away from the source site, the threedimensional nonhydrostatic MITgcm was set up using a zonal grid resolution of $100 \mathrm{~m}$ and approximately 650 million grid cells. The NIWs are well resolved by the numerical simulation and consistent with the in situ measurements. Although we cannot make a comparison between a modeled and the SAR observed wave front in our study region (Fig. 2e) because the present computation has approached the limit of our available computational power, the present simulation does show the capability of accurately simulating NIWs in the northeastern SCS while including deep basin in a ultrafine resolution region with a total 650 million grid (Simmons et al. 2011). Therefore, the present study gives an affirmative answer to the core question of Simmons et al. (2011) and provides unprecedented support for the application of ultrafine resolution simulations of NIWs at basin scales.

The three complementary methods used in this study are independent but interrelated with each other to illuminate the life cycle of the NIWs in the study region. The SAR captured the well-developed NIWs on the midshelf, while the synchronous in situ measurements were used to locate the preceding NIW counterparts near the shelf break. Subsequently, analyses of satellite and in situ observations combined with theoretical predictions of internal tide generation provide a wellfounded setup for the numerical model, which serves to verify the remote source site and reveal the generation mechanism of the observed NIWs.
Successful bridging among the three methods may inspire scientists to further demonstrate the remote source sites and generation mechanisms of NIWs in other important coastal oceans, such as the Malin Shelf (Small et al. 1999a), Mid-Atlantic Bight (Nash et al. 2012), and Washington Shelf (Zhang et al. 2015). In fact, Fig. 1 shows that occurrences of NIWs in the northwestern SCS span a wide area from east of Hainan Island to the south and then farther down to east of Vietnam. In general, NIW crests in that area are mostly parallel with the continental shelf break (water depth varies from 100 to $200 \mathrm{~m}$ ). Although our study area is to the southeast of Hainan Island and includes part of the abovementioned area, the findings reported here also offer important clues for investigating the generation and propagation of NIWs, which remain largely elusive in other nearby regions and offer an alternative perspective on the NIWs in other global coastal oceans, where the NIWs are dominated by shoaling internal tides from a remote source site.

A representative picture of NIW generation, propagation and evolution is provided by coherently linking the results from satellite observations, in situ measurements, numerical modeling and theoretical predictions. However, our decadal SAR observations (Fig. 1) show great temporal and spatial variability of NIW occurrence in our study region, indicating that internal tides may experience different reflection and refraction in the deep basin, probably caused by the variation of the stratification, meteorological event at the source site and background mesoscale currents. Consequently, longterm moorings are necessary to be projected to deploy at the Xisha Islands, in the deep basin and at the shelf break to reveal these scenarios and supplement the representative picture.

\section{Conclusions}

The life cycle of NIWs to the southeast of Hainan Island is reported by a synergistic analysis of spaceborne 
SAR observations, in situ measurements and numerical simulations. The main conclusions are as follows:

1) The NIWs emerging southeast of the Hainan Island originate from the Xisha Islands, which is approximately $215 \mathrm{~km}$ away from the local continental shelf where the NIWs are formed.

2) A diurnal internal tide emanates from the Xisha Islands, propagates through the deep basin in the form of a wave beam, and undergoes consecutive reflections at the sea bottom and near-surface thermocline in the westward propagation.

3) The diurnal internal tide initiates a strongly nonlinear transformation at the shelf break and excites short scale nonlinear bores.

4) The nonlinear bore continues to evolve into an internal solitary wave train on the midshelf.

Acknowledgments. The WOA13 temperature data, SRTM30_PLUS bathymetric data and TPXO tidal solutions were downloaded from the following websites: https://www.nodc.noaa.gov/OC5/woa13/, http:// topex.ucsd.edu/WWW_html/srtm30_plus.html, and http:// volkov.oce.orst.edu/tides/region.html, respectively. We thank the China Remote Sensing Satellite Ground Station, Airbus, Telespazio/ASI, and MDA for proving support on planning and acquiring the $G F-3, T S X$, CSK, and $R 2$ spaceborne SAR data. We specifically thank Prof. GuoPing Gao from the Shanghai Maritime University and $\mathrm{Mr}$. DengHui $\mathrm{Hu}$ from the Institute of Oceanology, Chinese Academy of Sciences, for their expert assistance in the deployment, recovery and operations of the in situ instruments. We are also grateful to Dr. Buijsman from the University of Southern Mississippi and Mr. Lequan Chi from Stony Brook University for providing valuable assistance in setting up the numerical model. The study was partially supported by grants from the National Natural Science Foundation of China project 41876201, Natural Science Foundation of Hainan Province Project 2016CXTD016, and the "Pioneered Hundred Talents Program," Chinese Academy of Sciences.

\section{REFERENCES}

Alford, M. H., 2003: Redistribution of energy available for ocean mixing by long-range propagation of internal waves. Nature, 423, 159-162, https://doi.org/10.1038/nature01628.

, R. Lien, H. Simmons, J. Klymak, S. Ramp, Y. J. Yang, D. Tang, and M. Chang, 2010: Speed and evolution of nonlinear internal waves transiting the South China Sea. J. Phys. Oceanogr., 40, 1338-1355, https://doi.org/10.1175/2010JPO4388.1.

- , and Coauthors, 2015: The formation and fate of internal waves in the South China Sea. Nature, 521, 65-69, https:// doi.org/10.1038/nature14399.
Alpers, W., 1985: Theory of radar imaging of internal waves. $\mathrm{Na}$ ture, 314, 245-247, https://doi.org/10.1038/314245a0.

Baines, P. G., 1982: On internal tide generation models. Deep Sea Res., 29A, 307-338, https://doi.org/10.1016/0198-0149(82) 90098-X.

Bogucki, D., T. Dickey, and L. G. Redekopp, 1997: Sediment resuspension and mixing by resonantly generated internal solitary waves. J. Phys. Oceanogr., 27, 1181-1196, https://doi.org/ 10.1175/1520-0485(1997)027<1181:SRAMBR>2.0.CO;2.

Brandt, P., A. Rubino, W. Alpers, and J. O. Backhaus, 1997: Internal waves in the strait of Messina studied by a numerical model and synthetic aperture radar images from the ERS $1 / 2$ Satellites. J. Phys. Oceanogr., 27, 648-663, https://doi.org/ 10.1175/1520-0485(1997)027<0648:IWITSO>2.0.CO;2.

Chang, M.-H., R.-C. Lien, T. Y. Tang, E. A. D'Asaro, and Y. J. Yang, 2006: Energy flux of nonlinear internal waves in northern South China Sea. Geophys. Res. Lett., 33, L03607, https://doi.org/ 10.1029/2005GL025196.

Chiu, C.-S., S. R. Ramp, C. W. Miller, J. F. Lynch, T. F. Duda, and T. Y. Tang, 2004: Acoustic intensity fluctuations induced by South China Sea internal tides and solitons. IEEE J. Oceanic Eng., 29, 1249-1263, https://doi.org/10.1109/JOE.2004.834173.

Cole, S. T., D. L. Rudnick, B. A. Hodges, and J. P. Martin, 2009: Observations of Tidal internal wave beams at Kauai Channel, Hawaii. J. Phys. Oceanogr., 39, 421-436, https://doi.org/10.1175/ 2008JPO3937.1.

Colosi, J. A., R. C. Beardsley, J. F. Lynch, G. Gawarkiewicz, C.-S. Chiu, and A. Scotti, 2001: Observations of nonlinear internal waves on the outer New England continental shelf during the summer Shelfbreak Primer study. J. Geophys. Res. 106, 9587-9601, https://doi.org/10.1029/2000JC900124.

Egbert, G. D., and R. D. Ray, 2000: Significant dissipation of tidal energy in the deep ocean inferred from satellite altimeter data. Nature, 405, 775, https://doi.org/10.1038/35015531.

_- and S. Y. Erofeeva, 2002: Efficient inverse modeling of barotropic ocean tides. J. Atmos. Oceanic Technol., 19, 183-204, https:// doi.org/10.1175/1520-0426(2002)019<0183:EIMOBO>2.0.CO;2.

Gill, A. E., 1982: Atmosphere-Ocean Dynamics. International Geophysics Series, Vol. 30, Academic Press, 662 pp.

Guo, C. C., and X. E. Chen, 2014: A review of internal solitary wave dynamics in the northern South China Sea. Prog. Oceanogr. 121, 7-23, https://doi.org/10.1016/j.pocean.2013.04.002.

Helfrich, K. R., and W. K. Melville, 2006: Long nonlinear internal waves. Annu. Rev. Fluid Mech., 38, 395-425, https://doi.org/ 10.1146/annurev.fluid.38.050304.092129.

_ , and R. H. J. Grimshaw, 2008: Nonlinear disintegration of the internal tide. J. Phys. Oceanogr., 38, 686-701, https://doi.org/ 10.1175/2007JPO3826.1.

Holloway, P. E., 1987: Internal hydraulic jumps and solitons at a shelf break region on the Australian North West Shelf. J. Geophys. Res., 92, 5405-5416, https://doi.org/10.1029/JC092iC05p05405.

Inall, M. E., T. P. Rippeth, and T. J. Sherwin, 2000: Impact of nonlinear waves on the dissipation of internal tidal energy at a shelf break. J. Geophys. Res., 105, 8687-8705, https://doi.org/ 10.1029/1999JC900299.

IOC/SCOR/IAPSO, 2010: The international thermodynamic equation of seawater - 2010: Calculation and use of thermodynamic properties. Intergovernmental Oceanographic Commission, Manuals and Guides 56, UNESCO, 196 pp., http://www.teos-10.org/pubs/TEOS-10_Manual.pdf.

Jackson, C. R., 2004: An Atlas of Internal Solitary-Like Waves and Their Properties. 2nd ed., http://www.internalwaveatlas.com/ Atlas2_index.html. 
— J. C. B. da Silva, G. Jeans, W. Alpers, and M. J. Caruso, 2013: Nonlinear internal waves in synthetic aperture radar imagery. Oceanography, 26, 68-79, https://doi.org/10.5670/oceanog.2013.32.

Jia, T., J. J. Liang, X.-M. Li, and J. Sha, 2018: SAR observation and numerical simulation of internal solitary wave refraction and reconnection behind the Dongsha Atoll. J. Geophys. Res. Oceans, 123, 74-89, https://doi.org/10.1002/2017JC013389.

Klymak, J. M., and S. M. Legg, 2010: A simple mixing scheme for models that resolve breaking internal waves. Ocean Modell., 33, 224-234, https://doi.org/10.1016/j.ocemod.2010.02.005.

—, R. Pinkel, C.-T. Liu, A. K. Liu, and L. David, 2006: Prototypical solitons in the South China Sea. Geophys. Res. Lett., 33, L11607, https://doi.org/10.1029/2006GL025932.

Lamb, K. G., 2014: Internal wave breaking and dissipation mechanisms on the continental slope/shelf. Annu. Rev. Fluid Mech., 46, 231-254, https://doi.org/10.1146/annurev-fluid-011212-140701.

Lavelle, J. W., and W. C. Thacker, 2008: A pretty good sponge: dealing with open boundaries in limited-area ocean models. Ocean Modell., 20, 270-292, https://doi.org/10.1016/j.ocemod.2007.10.002.

Li, D., X. Chen, and A. Liu, 2011: On the generation and evolution of internal solitary waves in the northwestern South China Sea. Ocean Modell., 40, 105-119, https://doi.org/10.1016/ j.ocemod.2011.08.005.

Li, Q., and D. M. Farmer, 2011: The generation and evolution of nonlinear internal waves in the deep basin of the South China Sea. J. Phys. Oceanogr., 41, 1345-1363, https://doi.org/10.1175/ 2011JPO4587.1.

Li, X. F., Z. X. Zhao, and W. G. Pichel, 2008: Internal solitary waves in the northwestern South China Sea inferred from satellite images. Geophys. Res. Lett., 35, L13605, https://doi.org/10.1029/ 2008GL034272.

—, C. R. Jackson, and W. G. Pichel, 2013: Internal solitary wave refraction at Dongsha Atoll, South China Sea. Geophys. Res. Lett., 40, 3128-3132, https://doi.org/10.1002/grl.50614.

Liu, A. K., and M. K. Hsu, 2004: Internal wave study in the South China Sea using synthetic aperture radar (SAR). Int. J. Remote Sens., 25, 1261-1264, https://doi.org/10.1080/01431160310001592148.

_- Y. S. Chang, M.-K. Hsu, and N. K. Liang, 1998: Evolution of nonlinear internal waves in the East and South China Seas. J. Geophys. Res., 103, 7995-8008, https://doi.org/10.1029/ 97JC01918.

Locarnini, R. A., and Coauthors, 2013: Temperature. Vol. 1, World Ocean Atlas 2013, NOAA Atlas NESDIS 73, 40 pp., http:// data.nodc.noaa.gov/woa/WOA13/DOC/woa13_vol1.pdf.

MacKinnon, J. A., and Coauthors, 2017: Climate process team on internal wave-driven ocean mixing. Bull. Amer. Meteor. Soc., 98, 2429-2454, https://doi.org/10.1175/BAMS-D-16-0030.1.

- - and M. C. Gregg, 2003: Mixing on the late-summer New England Shelf-Solibores, shear, and stratification. J. Phys. Oceanogr., 33, 1476-1492, https://doi.org/10.1175/ 1520-0485(2003)033<1476:MOTLNE $>2.0 . \mathrm{CO} ; 2$.

Marshall, J., A. Adcroft, C. Hill, L. Perelman, and C. Heisey, 1997: A finite-volume, incompressible Navier Stokes model for studies of the ocean on parallel computers. J. Geophys. Res., 102, 5753-5766, https://doi.org/10.1029/96JC02775.

Mathur, M., and T. Peacock, 2009: Internal wave beam propagation in non-uniform stratifications. J. Fluid Mech., 639, 133-152, https:// doi.org/10.1017/S0022112009991236.

Moum, J. N., D. M. Farmer, W. D. Smyth, L. Armi, and S. Vagle, 2003: Structure and generation of turbulence at Interfaces strained by internal solitary waves propagating shoreward over the continental shelf. J. Phys. Oceanogr., 33, 2093-2112, https://doi.org/ 10.1175/1520-0485(2003)033<2093:SAGOTA > 2.0.CO;2.

Munk, W., and C. Wunsch, 1998: Abyssal recipes II: Energetics of tidal and wind mixing. Deep-Sea Res. I, 45, 1977-2010, https:// doi.org/10.1016/S0967-0637(98)00070-3.

Nash, J. D., S. M. Kelly, E. L. Shroyer, J. N. Moum, and T. F. Duda, 2012: The unpredictable nature of internal tides on continental shelves. J. Phys. Oceanogr., 42, 1981-2000, https://doi.org/ 10.1175/JPO-D-12-028.1.

Osborne, A. R., and T. L. Burch, 1980: Internal solitons in the Andaman Sea. Science, 208, 451-460, https://doi.org/10.1126/ science.208.4443.451.

Sandstrom, H., and J. A. Elliott, 1984: Internal tide and solitons on the Scotian Shelf: A nutrient pump at work. J. Geophys. Res., 89, 6415-6426, https://doi.org/10.1029/JC089iC04p06415.

and N. S. Oakey, 1995: Dissipation in internal tides and solitary waves. J. Phys. Oceanogr., 25, 604-614, https://doi.org/ 10.1175/1520-0485(1995)025<0604:DIITAS > 2.0.CO;2.

Shroyer, E. L., J. N. Moum, and J. D. Nash, 2011: Nonlinear internal waves over New Jersey's continental shelf. J. Geophys. Res., 116, C03022, https://doi.org/10.1029/2010JC006332.

Simmons, H., M. H. Chang, Y. T. Chang, S. Y. Chao, O. Fringer, C. R. Jackson, and D. S. Ko, 2011: Modeling and prediction of internal waves in the South China Sea. Oceanography, 24, 88-99, https://doi.org/10.5670/oceanog.2011.97.

Small, J., Z. Hallock, G. Pavey, and J. Scott, 1999a: Observations of large amplitude internal waves at the Malin Shelf edge during SESAME 1995. Cont. Shelf Res., 19, 1389-1436, https:// doi.org/10.1016/S0278-4343(99)00023-0.

— T. C. Sawyer, and J. C. Scott, 1999b: The evolution of an internal bore at the Malin shelf break. Ann. Geophys. Germany, 17, 547-565, https://doi.org/10.1007/s00585-999-0547-x.

Smith, W. H. F., and D. T. Sandwell, 1997: Global sea floor topography from satellite altimetry and ship depth soundings. Science, 277, 1956-1962, https://doi.org/10.1126/science.277.5334.1956.

Vlasenko, V., N. Stashchuk, M. E. Inall, and J. E. Hopkins, 2014: Tidal energy conversion in a global hot spot: On the 3-D dynamics of baroclinic tides at the Celtic Sea shelf break. J. Geophys. Res. Oceans, 119, 3249-3265, https://doi.org/10.1002/ 2013JC009708.

Wang, J., W. G. Huang, J. S. Yang, H. G. Zhang, and G. Zheng, 2013: Study of the propagation direction of the internal waves in the South China Sea using satellite images. Acta Oceanol. Sin., 32, 42-50, https://doi.org/10.1007/s13131-013-0312-6.

Xu, J. X., Z. W. Chen, J. S. Xie, and S. Q. Cai, 2016: On generation and evolution of seaward propagating internal solitary waves in the northwestern South China Sea. Commun. Nonlinear Sci., 32, 122-136, https://doi.org/10.1016/j.cnsns.2015.08.013.

Xu, Z. H., B. S. Yin, Y. J. Hou, Z. S. Fan, and A. K. Liu, 2010: A study of internal solitary waves observed on the continental shelf in the northwestern South China Sea. Acta Oceanol. Sin., 29, 18-25, https://doi.org/10.1007/s13131-010-0033-z.

Zhang, S., M. H. Alford, and J. B. Mickett, 2015: Characteristics, generation and mass transport of nonlinear internal waves on the Washington continental shelf. J. Geophys. Res., 120, 741-758, https://doi.org/10.1002/2014JC010393.

Zhao, Z., 2014: Internal tide radiation from the Luzon Strait. J. Geophys. Res. Oceans, 119, 5434-5448, https://doi.org/10.1002/ 2014JC010014. 